\title{
Gamification Approach in Teaching Web Programming Courses in PHP: Use of KAHOOT Application
}

\author{
Ibrahim Ouahbi \\ Department of Educational Technologies, Faculty of Educational Sciences, Mohammed V University in Rabat, \\ Morocco \\ Email: i.ouahbi@um5s.net.ma
}

Hassane Darhmaoui

Center for Learning Technologies, Al Akhawayn University in Ifrane, Morocco

Email: h.darhmaoui@aui.ma

\section{Fatiha Kaddari}

Faculty of Sciences Dhar El Mahraz, University Sidi Mohammed Ben Abdellah, Fez, Morocco

Email: kaddari@yahoo.fr

Received: 23 October 2020; Accepted: 18 January 2021; Published: 08 April 2021

\begin{abstract}
Learning algorithmics and programming fundamental courses is widely considered to be quite challenging in the field of computer science. Gamification is a good alternative educational practice to promote programming teaching, it allows better engagement of students in their learning. Students acquire a reasonable level of abstraction and logic and develop reflections on various course concepts. They are better introduced to critical programming situations. In the present work, we investigated the impact of introducing simple gamified educational sequences within a dynamic programming PHP course on first year Master students in Educational Technology and Pedagogical Engineering (TEIP). Our use of gamification learning sequences based on the application KAHOOT in this course revealed a better engagement of students. $90 \%$ of the students in our experimental group expressed being more motivated and committed for the course and $87.5 \%$ of them expressed positive attitudes on using KAHOOT as a teaching tool. The majority (90\%) expressed their intention to recommend KAHOOT to other teachers.
\end{abstract}

Index Terms: Gamification, Web programming, Kahoot, Learning experience, ICT.

\section{Introduction}

Programming is among the fundamental concepts of Computer Science (CS) $[1,2,3,4]$, curriculum innovation and reform in CS discipline has recently become one of the most discussed and debated topics in educational policies [5,6,7]. There is a growing emphasis on the teaching of algorithmic, logic and programming in all disciplinary fields [2]. Indeed, the teaching of informatic as a science allows the development of high-level transversal skills such as communication, sharing, critical thinking, problem solving, autonomy, creativity, etc. [8]. In addition, CS has the capacity to be integrated in various fields: mathematics, natural sciences, physical sciences, medicine, engineering, educational sciences, arts, literature, law, etc. [9]. However, dropout rates in introductory algorithmic and programming courses are higher compared to other courses [10,11,12,13]. Learning fundamental concepts of programming still presents a number of difficulties and obstacles for beginners [10, 11, 14, 15]. Indeed, concepts structuring these courses present several difficulties and obstacles such as program construction, manipulation of loops, structure control, and algorithms. This leads to a negative perception and a lack of interest and motivation among learners $[16,17]$. To overcome these difficulties, a number of researchers recommended the use of gamified activities in teaching programming concepts [2, $7,8,10,18]$. These researchers are almost unanimous on the positive impact of gamification in learning the basics of programming concepts.

In this paper we present the implementation of a pedagogical sequence based on gamified activities in a PHP programming course destined to first year master students in the program Educational Technologies and Pedagogical Engineering (TEIP). We report increasing students' satisfaction and appreciation about this innovative methodology. 
Students in our experimental group were first invited to answer a questionnaire and to perform a quiz developed with the application KAHOOT ${ }^{1}$. The goal is to learn about their prior experience with educational games and to evaluate their proficiency in programming with HTML and CSS. After that, students followed an introduction to algorithmics and programming using gamified activities based on Blockley ${ }^{2}$ and Light-Bot ${ }^{3}$. They were also introduced to the basics of algorithmics and learned how to make simple programs using Scratch environment [19]. Then they followed a dynamic programming course with PHP. At the end of each session, the participating students were asked to use KAHOOT to develop online quizzes about the covered concepts.

The use of gamified activities and the use of KAHOOT application in the classroom, gave students the opportunity to become more engaged in their learning in a competitive environment and to self-evaluate themselves. Our results show students growing interest in PHP programming courses following our methodology

\section{State of the Art}

\section{A. Gamification and Serious Game}

The popularity of entertainment games among young people has prompted education researchers to explore this trend and to study the use of the cognitive power of digital games to motivate students and engage them more in their learning [20]. Since then, the pedagogical interest of games has been increasingly highlighted under other names, namely "Serious Games", "Gamification", "Educational Game" [21], etc.

The term Serious Game is generally used in IT context. This limitation of Serious Games to video games and computer media was initiated by the work of Ben Sawyer and David Rejeski, authors of the white paper: "Improving Public Policy through Game Based Learning and Simulations" [22]. Alvarez proposed a synthetic definition that implements a characteristic specific to Serious Games, namely the pedagogical scenario: Serious Game is an "application whose initial intention is to combine, in a coherent way, both serious aspects (Serious such as, in a nonexhaustive and non-exclusive way, teaching, learning, communication, or information), with playful springs from video games (Game). Such an association, which takes place through the implementation of a "pedagogical scenario", which on the computer level would correspond to the implementation of a (sound and graphic) dressing, a story and appropriate rules, is thus intended to move away from simple entertainment. This deviation seems to be indexed to the importance of the pedagogical scenario" [23].

Gamification is basically a general term for making the user's participation an enjoyable activity [24]: it's a broader concept than Serious Games, the idea is to use games and game design elements (rewards, points, levels, resources, missions, characters or avatars, progression, challenges, feedback, collaboration, luck ... ) in non-playful contexts [25]. Alomari et al, [26] reviewed several gamification techniques that can be used in different university courses. The results showed the role of certain game elements such as points, badges and leader boards in effective learning and in maintaining learner motivation and engagement. While Serious Games are most often presented in the form of a video game and used to increase intrinsic motivation, gamification is not necessarily a game and it allows for more extrinsic motivation.

\section{B. Related Work}

The recognition of the pedagogical potential of gamification in education has led to an increasing number of experiments in course gamification. Thongmak [1] explored the impact of using simple card games with a playful evaluation activity in an object-oriented programming course that focuses on student motivation and engagement. The majority of his students after his experiment felt more motivated to learn programming and the learning activities made them more engaging. Jen et al. [10] achieved similar results after applying gamification to their Java programming courses. Fotaris et al. [13] studied the impact of gamification on students' learning of Python programming. The experimental group in their study performed better in terms of commitment and final grades than the control group who took the programming courses in the traditional way. Tessler et al. [27] introduced the notion of recursivity through the serious game Cargo-Bot. At the end of their experiment, the authors noticed significant improvements on students' understanding of recursivity. $\mathrm{Ng}$ et al. [11] introduced gamification in their web programming courses in a blended collaborative learning environment and measured student motivation and engagement. Quizzes completed by students after their course were of a high quality that implied the increased motivation and commitment of students to learning web programming. Wolber [28] introduced his students to programming via the creation of mobile applications (quizzes, games ...) using the App Inventor environment. In addition to learning the basics of programming, students learned to use the App Inventor environment to create mobile applications that are useful in real-life situations, motivating them to engage in solving more complicated logical problems.

These bibliographical studies clearly show that the gamification in the course of programming is a priori positive:

\footnotetext{
${ }^{1}$ https://kahoot.com/

${ }^{2}$ https://blockly-games.appspot.com/?lang=fr

${ }^{3}$ http://armorgames.com/play/6061/light-bot-20
} 
- Learners are involved in a context more or less in line with their experiences, which increases their motivation and commitment and improves their perception of programming, which can only enhance their learning;

- Learners acquire the basic notions of programming;

- In addition to disciplinary skills, learners develop transversal skills $\left(21^{\text {st }}\right.$ century skills: creativity, teamwork, communication, etc.)

In the present work we are implementing gamification in teaching Web programming to first year TEIP master students. We opted for a well-defined approach combining both serious games and self-assessment tools that allowed us to reach the learning objectives of the course.

\section{Materials and Methods}

\section{A. Context of the experiment}

The experiment was carried out within the framework of the "PHP WEB programming" module for the benefit of 32 students of the first year of the TEIP Master ${ }^{4}$ at the Faculty of Educational Sciences (FSE-Rabat). This module provides students with the basic concepts of PHP programming, in order to develop pedagogical WEB applications.

\section{B. Objective}

The targeted competences and the associated knowledge which concretize the contents of the elaborated pedagogical sequences are described in the description of the PHP WEB programming module. The objective of the experiment is to study the impact of gamification on the perceptions, motivation and commitment of students in their learning.

\section{Tool used}

We used the application KAHOOT, which is a game-based learning platform that allows for the design and the elaboration of interactive quizzes (Fig. 1). The application could be used on smartphones as well as on computers.

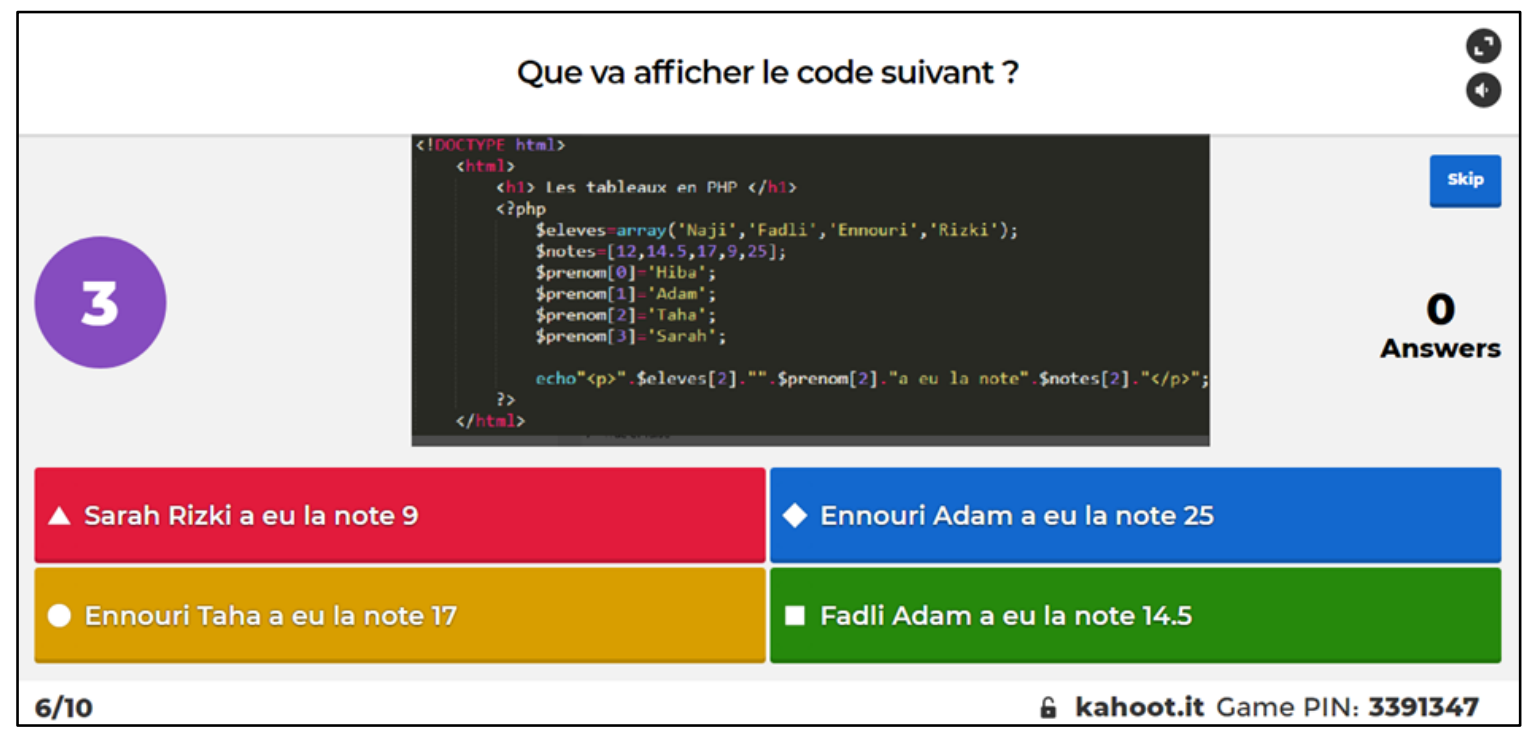

Fig. 1. Example of a KAHOOT question made by students

\section{Conduct of the experiment}

The experiment was carried out at the FSE during five sessions of the PHP web programming module, in a multimedia room with Internet access. The methodology followed is illustrated in the diagram below (Fig. 2): 


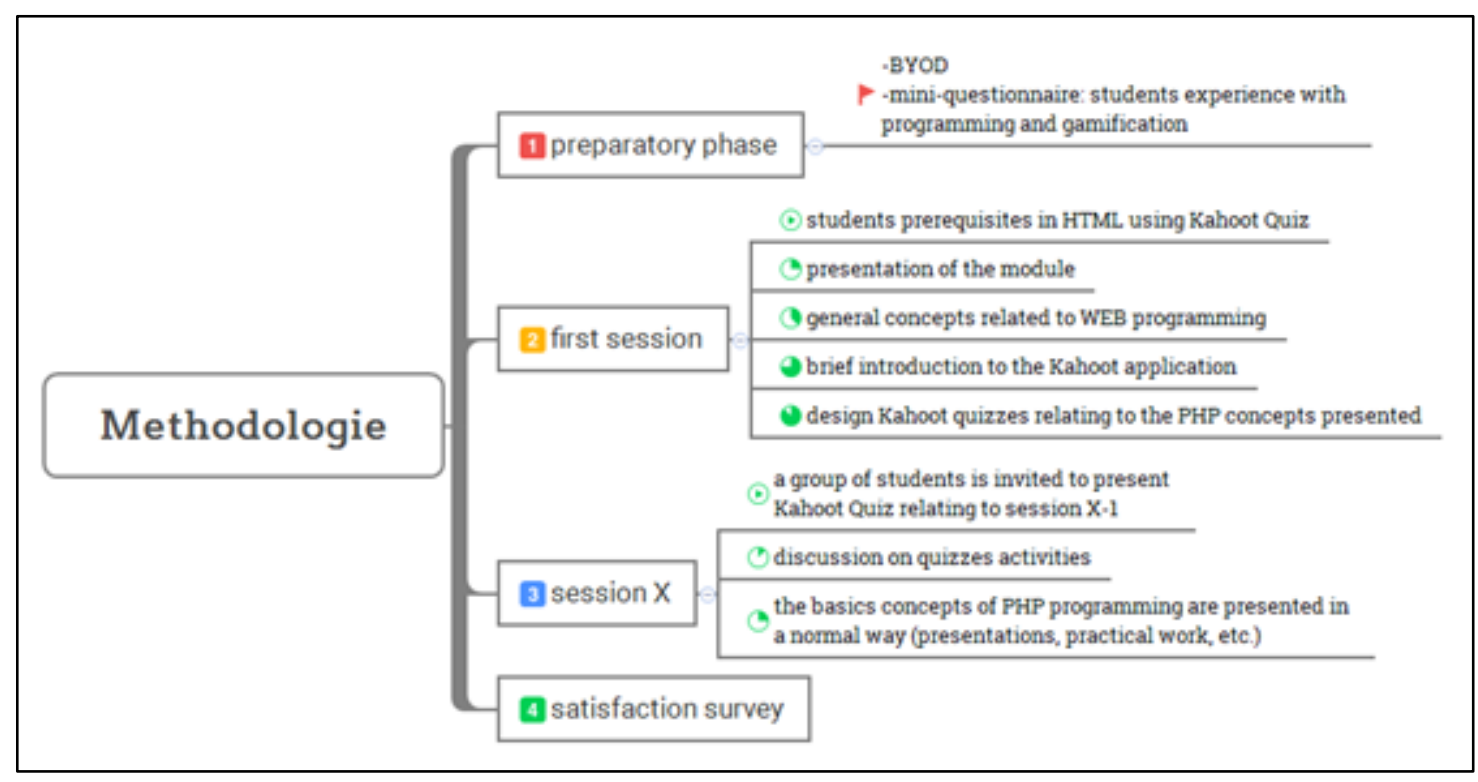

Fig. 2. Methodology

Before starting the experiment, the students were invited to answer a mini-questionnaire using their own mobile devices, the goal was to approach their experience with programming and playful applications. During the first session, the students were invited to answer a quiz made with the application KAHOOT. The objective was to test their prerequisites in HTML and CSS. Students then followed an introduction to algorithmics and programming using gamified activities: Blockley, Light-Bot and Scratch environment. After introducing the program of the PHP Web programming module, we presented general concepts related to Web programming. At the end of this first session, the students have attended a hands-on training on KAHOOT application where students were invited to design quizzes related to the PHP programming concepts that were presented during this first session. They were instructed to develop similar quizzes for future sessions of the module, and to share them with the instructor via Google Classroom. At the beginning of a new session, the instructor shared the developed KAHOOT quizzes of the previous session with all students and invited them to play/answer all of them outside of class time. In each session, a group of students was given 10 minutes to present the quiz they have developed right after the basics of PHP programming are presented in a normal way that consists of a PowerPoint presentation, a practical exercise, and tutorials.

To assess the attitudes and perceptions of the participating students about the experiment, at the end of the PHP Web programming module, all students were asked to fill a paper-based satisfaction survey in class. The questionnaire consisted of 15 questions on a Likert scale [29] from 1 to 5. Five response modalities are attributed to these closed questions (Strongly disagree $(\mathrm{cf}=1)$; Disagree $(\mathrm{cf}=2)$; Neither agree nor disagree $(\mathrm{cf}=3)$; Agree $(\mathrm{cf}=4)$; Strongly agree $(\mathrm{cf}=5))$. The questionnaire is divided into three parts: The first part of the questionnaire measures the students' commitment and motivation during the experiment, the second concerns the participants' perception of the learning/teaching results and the third identifies their perceptions on the use of KAHOOT and ICT in education.

\section{E. Data collection and processing}

Statistical processing of the collected data was carried out using SPSS software and Microsoft Excel. We note that the value of Cronbach's alpha coefficient associated with the questionnaire satisfaction is 0.74 which is greater than the minimum required threshold of 0.70 [30]. This indicates that the internal consistency of the questions asked is satisfactory.

\section{Results and Discussion}

\section{A. Experience with programming and fun applications}

Of the 32 students in our experiment, only two students reported having prior experience with courses incorporating digital games. This finding corroborates the data from a previous study of the perceptions of 180 trainee teachers of serious games that the majority of these future teachers were not familiar with the terms serious games and gamification, and the percentage of those who reported having experimented with digital games in their school curriculum did not exceed $11.67 \%$ [31].

In addition, 22 students said they have had experience with a programming language, of these 22 students, 10 said they had an introduction to Web programming. This shows that about $70 \%$ of the students have a beginner level in Web programming. This is due to the variety of students' profiles in the TEIP Master. 


\section{B. Satisfaction questionnaire}

\section{Students' commitment and motivation}

Table 1 shows a summary of students' responses to questions Q1 to Q6 which probe students' commitment and motivation. More than $90 \%$ of the participants (who either strongly agree or just agree) were motivated and committed, they considered the experimentation environment to be comforting and competitive. $87.50 \%$ of students reported that they were focused during the experimental class sessions and $78 \%$ of students said they had the opportunity to express their ideas with others.

Table 1. Responses to questions Q1 to Q6 of the survey (N=32)

\begin{tabular}{|c|c|c|c|c|c|c|}
\hline During the experiment & Mean & SD & D & $\mathbf{N}$ & $\mathbf{A}$ & SA \\
\hline Q1. I was very focused in class & 4,5 & $0,00 \%$ & $0,00 \%$ & $12,50 \%$ & $25,00 \%$ & $62,50 \%$ \\
\hline Q2. I interacted competitively in class & 4,406 & $0,00 \%$ & $6,25 \%$ & $3,13 \%$ & $34,38 \%$ & $56,25 \%$ \\
\hline Q3. I have had the opportunity to express my ideas with others. & 4,156 & $0,00 \%$ & $3,13 \%$ & $18,75 \%$ & $37,50 \%$ & $40,63 \%$ \\
\hline Q4. I felt comfortable. & 4,5 & $0,00 \%$ & $6,25 \%$ & $3,13 \%$ & $25,00 \%$ & $65,63 \%$ \\
\hline Q5. I was motivated to actively participate in the tasks requested. & 4,562 & $0,00 \%$ & $0,00 \%$ & $6,25 \%$ & $31,25 \%$ & $62,50 \%$ \\
\hline Q6. I was fully committed to completing the tasks requested. & 4,593 & $0,00 \%$ & $0,00 \%$ & $3,13 \%$ & $34,38 \%$ & $62,50 \%$ \\
\hline
\end{tabular}

\section{Students' perception of learning/teaching outcomes}

$64 \%$ of the students said that the use of play activities contributed to improving their understanding of basic programming concepts while $66 \%$ said that they received immediate feedback from the teacher.

\section{Students' perception of gamification (use of KAHOOT!)}

Table 2 shows a summary of the answers to questions Q9 to Q15 which probe students' perception of the use of the application KAHOOT. More than $87.5 \%$ of the students expressed positive attitudes on using KAHOOT as a teaching tool not only in a computer course but also in other school subjects. In addition, more than $90 \%$ of the students felt the fun and pedagogical aspect of the KAHOOT application and are motivated to seek and use other educational applications, in fact about $97 \%$ of the participants consider KAHOOT an interesting application to recommend to other teachers.

Students' involvement in the creation of quizzes allowed them to progress and produce concise and relevant questions which influenced their own mastery of the subject. This is due to the competitive environment of the gaming class where students try to challenge their peers by defining difficult and innovative questions. Overall, we feel that the students grasped the potential of gamification on motivating learners and were able to enrich their ICTE experience.

Table 2 Responses to questions Q9 to Q15 of the survey(N=32)

\begin{tabular}{|c|c|c|c|c|c|c|}
\hline Question & Mean & SD & D & $\mathbf{N}$ & $\mathbf{A}$ & SA \\
\hline $\begin{array}{l}\text { Q9. I think Kahoot! can be used as a teaching tool in all school } \\
\text { subjects. }\end{array}$ & 4,59 & $0,00 \%$ & $0,00 \%$ & $9,38 \%$ & $21,88 \%$ & $68,75 \%$ \\
\hline $\begin{array}{l}\text { Q10. I think that Kahoot! can be used in computer science } \\
\text { class. }\end{array}$ & 4,47 & $0,00 \%$ & $3,13 \%$ & $9,38 \%$ & $25,00 \%$ & $62,50 \%$ \\
\hline $\begin{array}{l}\text { Q11. I am interested in experimenting with Kahoot! in my } \\
\text { future teaching or learning experiences if given the } \\
\text { opportunity }\end{array}$ & 4,50 & $0,00 \%$ & $3,13 \%$ & $6,25 \%$ & $28,13 \%$ & $62,50 \%$ \\
\hline $\begin{array}{l}\text { Q12. Kahoot! is an interesting application to recommend to } \\
\text { teachers. }\end{array}$ & 4,56 & $0,00 \%$ & $0,00 \%$ & $3,13 \%$ & $37,50 \%$ & $59,38 \%$ \\
\hline $\begin{array}{l}\text { Q13 I am interested in experimenting with other online } \\
\text { educational applications in my future teaching or learning } \\
\text { experiences. }\end{array}$ & 4,66 & $0,00 \%$ & $0,00 \%$ & $6,25 \%$ & $21,88 \%$ & $71,88 \%$ \\
\hline $\begin{array}{l}\text { Q14 Kahoot! has encouraged me to seek and use other } \\
\text { educational applications. }\end{array}$ & 4,47 & $0,00 \%$ & $3,13 \%$ & $6,25 \%$ & $31,25 \%$ & $59,38 \%$ \\
\hline Q15: Kahoot! is a fun educational application. & 4,78 & $0,00 \%$ & $0,00 \%$ & $3,13 \%$ & $15,63 \%$ & $81,25 \%$ \\
\hline
\end{tabular}

\section{Conclusion}

In this article, we presented and evaluated a simple implementation of gamification in teaching Web programming courses in PHP that combines serious games and self-assessment. Students were invited to create and play Kahoot quizzes with PHP programming's concepts taught in class. This had a positive effect on the students' motivation and engagement in their learning. Students progressed in the realization of quality quizzes, and at the end of the experiment 
they succeeded in designing innovative and relevant questions. In addition to this, our approach has introduced our students in educational technologies to teaching pedagogies incorporating gamified teaching and learning. This helped them to better grasp the pedagogical potential of gamification. Indeed, more than $90 \%$ of the students were motivated to seek and use similar gamification tools and the majority (97\%) considered KAHOOT an interesting application worth recommending to other teachers.

\section{Acknowledgment}

We acknowledge the assistance of Mr. Mohammed Ouahbi in proofreading this paper. We are thankful to him.

\section{References}

[1] Thongmak, M. (2018). Creating gameful experience in the object-oriented programming classroom: A case study. Online Journal of Applied Knowledge Management (OJAKM), 6(1), 30-53.

[2] Combéfis, S., Beresnevičius, G., \& Dagienè, V. (2016). Learning programming through games and contests: overview, characterisation and discussion. Olympiads in Informatics, 10(1), 39-60.

[3] Yang, T. C., Hwang, G. J., Yang, S. J., \& Hwang, G. H. (2015). A two-tier test-based approach to improving students' computer-programming skills in a web-based learning environment. Journal of Educational Technology \& Society, 18(1), 198210.

[4] Biju, S. M. (2018). Best Approach to Teach Advanced Programming, International Journal of Education and Management Engineering (IJEME), Vol.8, No.6, pp.37-45, 2018.DOI:10.5815/ijeme.2018.06.04.

[5] Ouahbi, I., Darhmaoui, H., Kaddari, F., \& Bemmouna, A. (2019). Computer Science Program in Moroccan Secondary Schools: Curricula Analysis", International Journal of Modern Education and Computer Science (IJMECS), Vol.11, No.3, pp. 1015,2019. DOI:10.5815/ijmecs.2019.03.02.

[6] Duch, P., \& Jaworski, T. (2018). Enriching Computer Science Programming Classes with Arduino Game Development. In 2018 11th International Conference on Human System Interaction (HSI) (pp. 148-154). IEEE.

[7] Azmi, S., Iahad, N. A., \& Ahmad, N. (2015). Gamification in online collaborative learning for programming courses: A literature review. ARPN Journal of Engineering and Applied Sciences, 10(23), 1-3.

[8] Ouahbi, I., Kaddari, F., Darhmaoui, H., \& Elachqar, A. (2018). L'intégration des serious games dans les cours d'introduction de l'algorithmique et de la programmation : Integration of serious games in teaching an introductory course on algorithmic and programming. frantice.net, 14(1).

[9] Adhikari, K. (2019). Exploring girls' perception on Computing careers via educational quiz-application (Master's thesis, NTNU).

[10] Jen, L. S., \& Said, S. H. M. (2018). Application of gamification in introduction to programming: A case study. PEOPLE: International Journal of Social Sciences, 4(3).

[11] Ng, W. S., \& Cheng, G. (2018). A collaborative blended learning approach for learning web programming. Proceedings of International Conference on Information Communication Technologies in Education ICICTE 2018 (pp. 49-58).

[12] Wilson, C., Sudol, L. A. S., Stephenson, C., Stehlik, M., Acm, \& Csta. (2011). Running on empty: The Failure to Teach K-12 Computer Science in the Digital Age. Inquiry: A Journal of Medical Care Organization, Provision and Financing, 48(3), 17782.

[13] Robins, A., Rountree, J., \& Rountree, N. (2003). Learning and Teaching Programming: A Review and Discussion. Computer Science Education, 13(2), 137-172.

[14] Wang, X. M., Hwang, G. J., Liang, Z. Y., \& Wang, H. Y. (2017). Enhancing students' computer programming performances, critical thinking awareness and attitudes towards programming: An online peer-assessment attempt. Journal of Educational Technology \& Society, 20(4), 58-68.

[15] Ouahbi, I., Kaddari, F., Darhmaoui, H., Elachqar, A., \& Lahmine, S. (2015). Learning basic programming concepts by creating games with SCRATCH programming environment. Procedia-Social and Behavioral Sciences, 191, 1479-1482.

[16] Saliba, M., Kaddari, F., Elachqar, A., \& Chahwan, J. (2014). Comparative Study of the IT Teaching/Learning in School Contexts: Lebanese and Moroccan.Procedia-Social and Behavioral Sciences, 116, 4650-4653.

[17] Violino, B. (2009). Time to reboot. Communications of the ACM, 52(4), 19-19.

[18] Fotaris, P., Mastoras, T., Leinfellner, R., \& Rosunally, Y. (2015). From hiscore to high marks: Empirical study of teaching programming through gamification. In European Conference on Games Based Learning (p. 186). Academic Conferences International Limited.

[19] Malan, D. J., \& Leitner, H. H. (2007). Scratch for budding computer scientists. ACM Sigcse Bulletin, 39(1), $223-227$.

[20] Gee, J. P. (2005). Good video games and good learning. In Phi Kappa Phi Forum (Vol. 85, No. 2, p. 33). The Honor Society of Phi Kappa Phi.

[21] El Mhouti, A., Nasseh, A., \& Erradi, M. (2016). A Framework to Stimulate Collaborative e-Learning through Collaborative Educational Games Modeled Using IMS-LD, International Journal of Information Technology and Computer Science (IJITCS), Vol.8, No.4, pp.19-27, 2016. DOI: 10.5815/ijitcs.2016.04.03

[22] Sawyer, B., \& Rejeski, D. (2002). Serious Games: Improving public policy through game-based learning and simulation.

[23] Alvarez, J. (2007). Du jeu vidéo au Serious Game: approches culturelle, pragmatique et formelle (Doctoral dissertation, Toulouse 2).

[24] Ghanyani, U. S., Murad, M., \& Mahmood, W. (2018). Crowd-based Requirement Engineering, International Journal of Education and Management Engineering (IJEME), Vol.8, No.3, pp.43-53, 2018.DOI: 10.5815/ijeme.2018.03.05 
[25] Deterding, S., Sicart, M., Nacke, L., O'Hara, K., \& Dixon, D. (2011). Gamification. using game-design elements in non-gaming contexts. In CHI'11 extended abstracts on human factors in computing systems (pp. 2425-2428).

[26] Alomari, I., Al-Samarraie, H., \& Yousef, R. (2019). The Role of Gamification Techniques in Promoting Student Learning: A Review and Synthesis. Journal of Information Technology Education: Research, 18, 395-417.

[27] Tessler, J., Beth, B., \& Lin, C. (2013). Using cargo-bot to provide contextualized learning of recursion. In Proceedings of the ninth annual international ACM conference on International computing education research (pp. 161-168). ACM.

[28] Wolber, D. (2011). App inventor and real-world motivation. In Proceedings of the 42nd ACM technical symposium on Computer science education (pp. 601-606). ACM.

[29] Likert, R. (1932). A technique for the measurement of attitudes. Archives of psychology, 140, pp. 1-55.

[30] Taber, K. S. (2018). The use of Cronbach's alpha when developing and reporting research instruments in science education. Research in Science Education, 48(6), 1273-1296.

[31] Ouahbi, I., Darhmaoui, H., Kaddari, F., Elachqar, A., \& Lahmine, S. (2016). Pre-service Teachers' Perceptions and Awareness toward Serious Games in the Classroom-Case of Morocco. In 2016 13th International Conference on Computer Graphics, Imaging and Visualization (CGiV) (pp. 431-436). IEEE.

\section{Authors' Profiles}

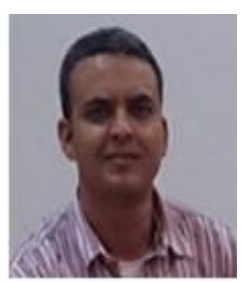

Ibrahim Ouahbi received his $\mathrm{PhD}$ degree in didactics of sciences in 2018 from Sidi Mohammed Ben Abdellah University, Faculty of Sciences Dhar Almahraz, Fez, Morocco. Presently, he teaches educational technologies at Faculty of Educational Sciences, Mohammed V University in Rabat. His research interests include computer science education and ICT integration in science education and learning.

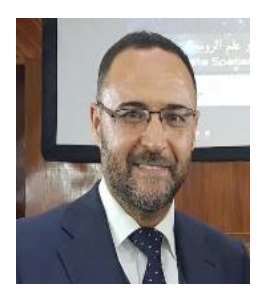

Hassane Darhmaoui got his PhD. in Physics from the University of Alberta Edmonton, Canada in 1997. He joined Al Akhawayn University (AUI) in 1997. He is currently an associate professor in the School of Science and Engineering. In 2009 he was appointed coordinator of the Center for Learning Technologies at AUI. His research in education includes ICT integration in science education and astronomy popularization.

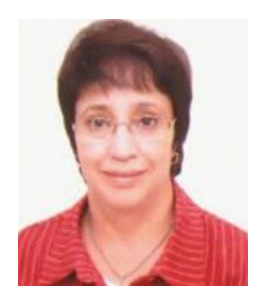

Fatiha Kaddari received her PhD degree in chemistry in 1997 from the Montpellier II University in France. In 2005, she received her second $\mathrm{PhD}$ degree in didactics of sciences. Her research interests in education include ICT integration in science and serious games

How to cite this paper: Ibrahim Ouahbi, Hassane Darhmaoui, Fatiha Kaddari, " Gamification Approach in Teaching Web Programming Courses in PHP: Use of KAHOOT Application", International Journal of Modern Education and Computer Science(IJMECS), Vol.13, No.2, pp. 33-39, 2021.DOI: 10.5815/ijmecs.2021.02.04 